East African Medical Journal Vol. 81. No. 5 May 2004

CERVICAL SPINAL TUBERCULOSIS WITH TUBERCULOUS OTITIS MEDIA MASQUERADING AS OTITIS EXTERNA MALIGNANS IN AN ELDERLY DIABETIC PATIENT: CASE REPORT

A. Aderibigbe, MBBS, FWACP., FMCP., Consultant Physician, Department of Medicine and F.E., Ologe MBBS, FWACS., FMCORL, Consultant Otoloryngologist, Department of Otorhinolaryngology, University of llorin Teaching Hospital, P.M.B. 1459, Ilorin 240001, Nigeria

Request for reprints to: Dr. A. Aderibigbe, Department of Medicine, University of Ilorin Teaching Hospital, P.M.B. 1459, Ilorin, Nigeria

\title{
CERVICAL SPINAL TUBERCULOSIS WITH TUBERCULOUS OTITIS MEDIA MASQUERADING AS OTITIS EXTERNA MALIGNANS IN AN ELDERLY DIABETIC PATIENT: CASE REPORT
}

\author{
A. ADERIBIGBE and F.E. OLOGE
}

\begin{abstract}
SUMMARY
Extrapulmonary manifestation of tuberculosis (Tb), a medieval disease, occurs in every part of the body with varying degree of frequency but commonly in the pleural and lymph nodes. When it occurs in bones thoracolumbar vertebrae is the usual site of involvement. Other bones are less involved hence seldomly reported. This is true for other organs and parts of the body including larynx, pharynx nose and the middle ear. More importantly, isolated extrapulmonary tuberculosis without pulmonary involvement is uncommon. The case of a 65 year old Nigerian trader who presented with headache, chronic ear ache with otorrhoea, persistent neck pain and found to be diabetic on further evaluation is presented. She was hitherto managed as a case of otitis external malignans without any improvement but rather her clinical condition worsened with evidence of cervical vertebra destruction and multiple cranial nerve palsies without pulmonary tuberculosis. Prompt and effective response to anti tuberculosis drugs informed the diagnosis of tuberculosis of the cervical vertebra and tuberculous otitis media with multiple cranial nerve palsies. This case underscores the value of high index of suspicion, thorough and complete clinical evaluation in any patient with chronic symptoms and signs unresponsive to conventional treatment.
\end{abstract}

\section{INTRODUCTION}

Tuberculosis is one of the oldest diseases known to man. Its chronicity, morbidity, and mortality with attendant economic loss have made it one of the most dreadful diseases worldwide. Tuberculosis infection caused by mycobacterium tubercle spreads from person to person by droplets nuclei and within the body spread is via blood and the Iymphatics. The organism is resilient and dormant and can remain inactive for years in its host. It becomes active when host immune status is compromised particularly in malnutrition, diabetes mellitus and recently HIV infection. Until mid 1980s, when the incidence of HIV infection worldwide started rising, notified tuberculosis cases were decreasing. In patients with more marked immunodeficiency, with CD4 counts of less than $200 \mathrm{~mm}^{3}$, the features of $\mathrm{Tb}$ are often atypical, with a much greater frequency of extrapulmonary involvement(1). Indeed, the HIV epidemic in sub-Saharan Africa accounts for more than two-thirds of all infections in the world(2).

At the beginning of the last century 3-5\% of cases of otitis media were due to tubercle bacillus however, this prevalence has reduced over time. In a 16 year period, 1959-1975, in Nigeria's foremost teaching hospital, University College Hospital, Ibadan, there were 24 cases an average of 1.5 a year with $75 \%$ occurring in the paediatric age group(3). Little has been reported in recent times of tuberculous otitis media in our environment. Okafor in the south eastern part of Nigeria reported only three cases of tuberculous otitis media among 1200 patients with chronic suppurative otitis media(4). This paper underscores the importance of tuberculosis infection in patients with chronic ear discharge, even without pulmonary manifestation. It also demonstrates the value of high index of suspicion in the evaluation of patients with symptoms of recurring chronic disease, not responding to conventional therapy.

\section{CASE REPORT}

A 65-year-old Nigerian woman trader was referred from a private clinic in llorin to the Medical outpatient Department of the University of llorin Teaching Hospital on account of chronic left ear ache, and throbbing generalized headache for three months. The left ear started to discharge dirty colour pus inspite of the conventional treatment at the private clinic, which included antibiotics, and anti fungal treatment among others.

Further evaluation revealed that she had polyuria, polydipsdia, recurrent boils tingling and peppery sensations on the feet. However, there was no blurring of vision or history of instrumentation to the ear. There was gradual weight loss despite good appetite. There was no significant history of cough, night sweat or diarrhoea. Her left arm blood pressure was $120 / 70 \mathrm{mHg}$ in the sitting 
position measured with mercury sphygmomanometer. Fundoscopy was essentially normal

All the other systems were essentially normal except the central nervous system where she had loss of sensation to light touch at the extremities. Her Fasting Blood Sugar (FBS) was $9.4 \mathrm{mmol}$, haemoglobin concentration was $12.0 \mathrm{~g} / \mathrm{L}$ and PCV $33 \%$, while serum urea and creatinine were within normal limits. Urinalysis showed glucosuria + but no ketone. A case of diabetes mellittus with otitis media was made and commenced on insulin and antibiotics and sent to an ENT surgeon for further evaluation.

When the ENT surgeon saw her one-week later, evaluation revealed, circumferential meatal stenosis, maximal at the cartilaginous portion of the meatus with apparent meatal abscess collection anteriorly and posteriorly. Tympanic membrane was obscured with debris suspected to be candida. There was weakness of the left side of the face (Figure 1). A tentative diagnosis of left otitis external malignans with left facial nerve palsy was made. Culture of the discharge yielded proteus mirabilis, staphylococcus aureus and candida spp. A repeat FBS was $9.2 \mathrm{mmol} / \mathrm{L}$. She was commenced on carbenicillin, gentamycin, magnesium sulphate paste application and antifungal drugs in addition to insulin therapy. She also had the care of the physiotherapist for the facial palsy. The skull $\mathrm{X}$-ray done was normal while the cervical vertebrae $\mathrm{X}$-ray showed marginal osteophytes in C1-C4 (Figure 2). The orthopaedic surgeon recommended cervical collar because of the neck pain and the marginal cervical osteophytes.

Despite the aggressive antibiotic therapy which included third generation cephalosporin, metronidazole in addition to earlier antimicrobial agents and the multidisciplinary approach to management for six months, the patient continued to lose weight and her clinical condition deteriorated. While on treatment she developed right hypoglossal nerve palsy (Figure 3). She developed slurred speech and inability to swallow. There was fixed flexion of the neck with intense headache and neck pain. The ear discharge became profuse, and now associated with hearing loss. However, there were no signs of meningeal irritation. Further ENT evaluation revealed a limited upward mobility of the soft palate, had rhinolalia operta and a central pinhole perforation of the tympanic membrane with a polypoid granulation in the middle ear. The granulation was excised under local anaesthesia and sent for histology. Histopathology result showed epitheliod cells, Iymphocyte and inflammatory cells. Repeat X-ray of the neck showed destruction of the cervical bodies - atlas and axis - with marked flexion deformities. There was partial destruction of the bodies of C3-C5 with some narrowing of the intervening disc spaces and a large prevertebral soft tissue collection. There was acute angular kyphosis at $\mathrm{C} 2 / 3$ level (Figure 4). Compared with the films done earlier, there had been a rather rapid progression of the destructive process. X-ray of the mastoids showed extensive destruction of mastoid air cells.
Figure 1

Facial nerve palsy (Lt) and neck stiffness

Figure 2

Marginal osteophytes at C3-5 of the cervical vertebral

Figure 3

Right hypoglossal nerve palsy

Figure 4

Total collapse of cervical spine between the atlas and axis and C4. There was marked flexion deformity. There was acute angular kyphosis at C2/3 level 
AFB was never positive in the discharging ear and there were no facilities for AFB culture. The ESR was $60 \mathrm{~mm} / \mathrm{hr}$ and the weight had dropped to $44 \mathrm{~kg}$ from $49.5 \mathrm{~kg}$ on first evaluation.

In view of the worsening condition and progressive destruction of the cervical vertebrae with added cranial nerve palsies (IX,X,XI,XII) to the facial nerve palsy, a diagnosis of cervical spinal tuberculosis with involvement of the middle ear and possibly extension to the base of the skull was entertained

She was commenced on anti tuberculous regimen isoniazid (INH), rifampicin, pyrazinamide and streptomycin. Within six weeks of commencing treatment she made significant improvement. She was then offered a nine month anti tuberculosis course. The otorrhoea ceased, the tympanic membrane perforation healed, the affected cranial nerves recovered; the cervical vertebrae destruction was arrested and the diabetes mellitus became controlled on oral hypoglycaemic drugs. ESR dropped to $20 \mathrm{~mm} / \mathrm{hr}$ and she gained weight steadily.

She has been followed up for 10 years with sustained improvement and recovery. She currently attends the medical outpatient clinic for the diabetes mellitus, which is well controlled.

\section{DISCUSSION}

Tuberculosis of the spine is still a common scourge in half of the world today $(5,6)$. The Thoracolumbar spine is most commonly affected, but the cervical spine could also be involved(5). Spinal tuberculosis, like other extra pulmonary tuberculosis, can occur without pulmonary involvement as in the case presented $(5,6)$. Expectedly, the prevalence is on the increase with the increasing prevalence of HIV infections(5).

She was not a diagnosed diabetic patient before presentation. She however had history of polyuria, polydipsdia, weight loss, recurrent boil, blurring of vision and burning and pin prick sensation particularly on both feet but no family history of diabetes mellitus or chronic cough. This justified the initial diagnosis of otitis malignans external. The cervical destruction and prompt response to anti tuberculosis therapy gave weight to our diagnosis.

Tuberculous otitis media in adults most commonly occurs in association with advanced pulmonary or extrapulmonary tuberculosis, but in children it may occur in isolation $(3,7)$. In Nigeria, cervical tuberculosis is the least common among the $\mathrm{Tb}$ of the spine(8). In this case report, cervical spinal tuberculosis was associated with tuberculous otitis media, in a previously undiagnosed diabetes mellitus patient. In established disease, there is a florid, pale granulation tissue in the middle ear behind an intact, but more often a perforated (characteristically multiple perforated) tympanic membrane. There is a disproportionately large hearing loss than in conventional chronic suppurative otitis media due to greater inner ear involvement. Extensive ragged destruction in the mastoid and middle ear rather than sclerosis is the typical radiographic feature(7).

Facial nerve palsy, which also occurs in other forms of chronic suppurative otitis media, is the most frequent complication(3). A high index of suspicion is necessary to make the diagnosis of extrapulmonary tuberculosis $(5,9)$. In significant proportion of cases the typical picture is not seen; clinical presentation is often similar to that of malignant disease and other chronic inflammatory lesions, thus delaying diagnosis and worsening the progression of the diseases $(5,9)$. This case advises clinician like others earlier reported to suspect tuberculosis when active disease does not respond to conventional medical or surgical management, as in the case presented. And in the case of tuberculous chronic suppurative otitis media, culturing the discharge for tubercle bacilli where the facilities are available and histological examination of the granulation tissue will promote prompt diagnosis and early treatment.

The overall picture of this patient justifies the differential diagnosis of otitis externa malignans initially pursued. This is an uncommon but progressive debilitating and sometimes fatal infection of the external meatus, surrounding soft tissues, and skull base(10). In this patient (IX, X, Xl) and Xll were probably involved via the spread of disease in the atlas and axis to the base of the skull.

The only surgical intervention was the excision of the granulation tissue in the middle ear, medical treatment, with other supportive treatment from the orthopaedic surgeon and physiotherapist were all that was required in our patient.

This is in keeping with the observations of other workers(5). Since there was no residual tympanic membrane defects, tympanoplasty was not needed. This case underscores the need for high index of suspicion in diabetics or non diabetes patients presenting with features mimicking otitis malignans externa or chronic otitis media not responding to conventional treatment. Early diagnosis which would no doubt reduce the attendant morbidity and mortality associated with the disease before it runs its full course.

\section{ACKNOWLEDGEMENTS}

To the late Prof. O. Ogan who was involved in the initial management of the case and Prof. F. Komolafe who read all the X-rays. The support of the staff of the Medical education illustrations unit of the University and the secretarial assistance rendered by Mr. Tosin Oluokun and Mrs. Obatusin of the Department of Medicine is also gratefully acknowledged.

\section{REFERENCES}

1. Schecter, G. F. Mycobacterium Tuberculosis infection In: The AIDS knowledge Base. Ed. Cohen, P. T., Saude, M. A., Volberding, P. A. 2nd Edition, New York: Little, Brown and company, 1994; pp 6.5-1 -6.5-6.

2. Graham, B. S. Infection with HIV-I. Brit. Med. J. 1998; 317:1297-1301. 
3. Ogan, O. Tuberculosis of the middle ear cleft In: Clinical Surgery in Ibadan. 1975; pp 66-72.

4. Okafor, B. C. Otolaryngology in Southern Eastern Nigeria 1: Pattern of disease of the ear. Nig. Med. J. 1983; 13: 11-19.

5. Ikem, I. C., Bamgboye, E. A. and Olasinde, A. A. Spinal Tuberculosis: A 15 year review at OAUTHC, lle-lfe. Nig. Postgraduate Med. J. 2001; 8:22-25.

6. Sayi, E. N. and Mlay, S. M. Tuberculosis of the spine in children at Muhimbili Medical Centre, Dar es Salaam. East Afr. Med. J. 1995; 72:46-48.
7. Phelps, P. D. Radiology of the Ear In: Scott-Brown's Otolaryngology. Otology 6th Ed: Ed. Kerr, A. G., Booth, J. B. Oxford: Butterworh/Heinemann 1997; 3/2/1-3/2/38.

8. Obisesan, M., Lagundoye, S. B. and Lawson, E. A. Radiological features of Tuberculosis of the Spine in Ibadan, Nigeria. Afr. J. Med. Sci. 1977; 6:55-69.

9. Pulplampu, B. Indices in the early diagnosis of tuberculosis of the spine in Ghana. West Afr. J. Med. 1998; 17:99-103.

10. Wright, D. Diseases of the external ear In: Scott-Brown's Otolaryngology: Otology 6th Ed. Ed Kerr, A. G., Booth, J. B., Oxford: Butterworth/Heinemann 1997; 3/6/1-/6/20. 